\title{
Steiner cephalometric analysis discrepancies between conventional and digital methods using CephNinja application software
}

\author{
Gita Gayatri*, Andriani Harsanti*, Yuliawati Zenab*, Iwa Rahmat Sunaryo* \\ *Department of Orthodontics Faculty of Dentistry Universitas Padjadjaran, Indonesia
}

\begin{abstract}
Introduction: Cephalometric analysis has been widely used in orthodontics, conducted in two methods: conventional and digital methods. Practitioners prefer using computerized cephalometric analysis due to its simplicity and less time-consuming compare to manual or conventional method. Purpose: The aim of this study was to identify discrepancy between conventional Steiner cephalometric analysis and digital cephalometric analysis using CephNinja application. This study was an experimental in vivo study with descriptive and comparative approach. Methods: Thirty two negative and digital cephalogram were traced manually using Steiner analysis and digitally using CephNinja software application. Tracing results of manually analyzed cephalogram and digitally analyzed cephalogram were then compared. Results: There was no distinguished discrepancy between the tracing results of both manually analyzed cephalogram using Steiner analysis and digitally analyzed cephalogram using CephNinja. Conclusion: There was no significant difference of Steiner cephalometric analysis conducted using conventional tracing and digital method using CephNinja application software.
\end{abstract}

Keywords: Analysis, CephNinja, Steiner cephalometric analysis.

\section{INTRODUCTION}

Cephalometric analysis has been used in the orthodontic field since it was discovered by Broadbent in 1931, especially in diagnosing, determining the treatment plan, evaluating the results of treatment, and predicting the growth and development..$^{1,2}$ In addition, the cephalometric analysis can be used to add dynamic aspects of diagnosis in determining better treatment plan, providing information about the morphology, facial growth pattern, craniofacial dimension, skeletal abnormalities, or dentoalveolar of an individual. ${ }^{2}$

The most frequently used cephalometric analysis is the Steiner analysis because it is easy to be used and fast. This analysis is one of the most popular analysis for orthodontic treatment planning and with a combination methods of Down's, Wendell Wylie, Brodie, Rickett's, Thomson, Riedel, and Holdaway methods. . $^{3,6,7}$

Cephalometric analysis can be done by two methods: conventional methods by means of manual tracing and computerized digital methods. Conventional cephalometric analysis was done by tracing the cephalometric radiograph on acetate paper by searching for landmarks to measure the lines and angles using protractors. ${ }^{4,9,10}$

The conventional cephalometric analysis method has several disadvantages such as requiring a long time in the fulfillment and has the high risk of miscalculation at tracing, identifying landmarks, and measuring angle and distance. ${ }^{6,7}$ 
A lot of practitioners has been choosing to use the computerized cephalometric analysis method to uphold diagnosis, determine the treatment plan and predict growth. Since more than 15 years ago, cephalometric analysis software has been known in the field of orthodontics. Cephalometric analysis using computer software is considered to simplify and save time in performing cephalometric analysis compared to conventional or manual methods. ${ }^{5}$ The use of computer software to perform cephalometric analysis allows practitioners to perform the measurement of angles and distances automatically so as to eliminate errors when practitioners draw a line between the two landmarks or measure angles using protractors. ${ }^{1,9}$

There is some specialized software that has been developed for cephalometric analysis includes OrthoCeph, Dolphin, Ax.Ceph, Faca, etc. Using analysis software has been very helpful for orthodontic practitioners in performing cephalometric analysis as well as for determining diagnosis and treatment plan. However, the cost to be incurred for the purchase of this software is quite expensive and the software is difficult to be obtained.

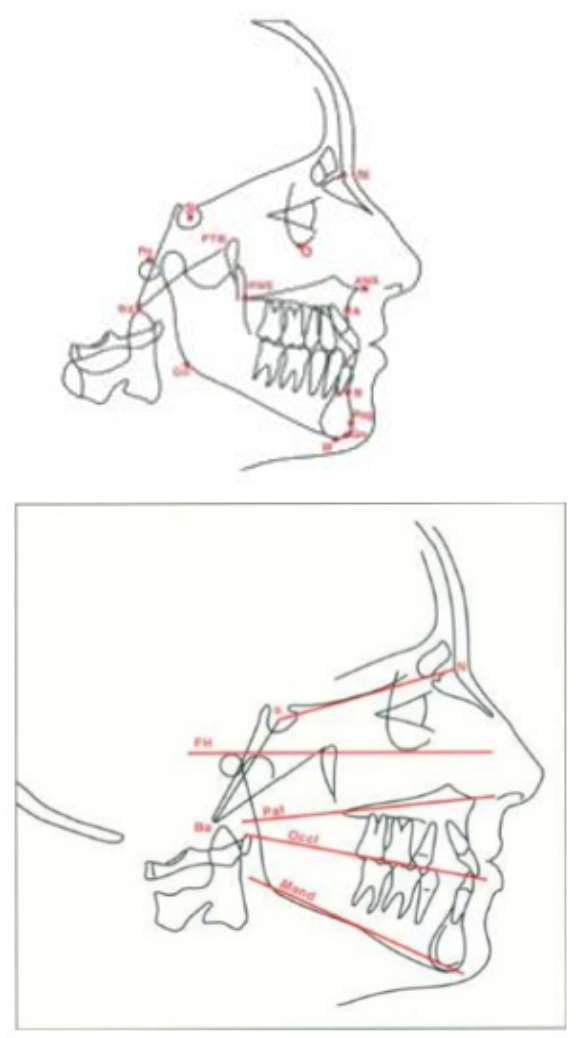

Fig 3. Cephninja application software
It has now been widely known among orthodontists, cephalometric analysis software in the application form which can be downloaded on devices that has the android and IOS operating system called CephNinja. CephNinja is designed to allow orthodontists in the process of analyzing cephalometric radiograph with the advantages of these applications such as it can be conducted anytime and anywhere because the software is compatible with any android or ios operating system.

Based on the above reason, the authors are interested to know the difference of Steiner cephalometric analysis results between the conventional method and a digital method using CephNinja application software.

\section{METHODS}

The research materials used were cephalogram negative x-rays, digital cepha-logram in JPEG format and acetate paper. Research tools used were negatoskop, $4 \mathrm{H}$ pencil, adhesive (taped), protractors brands Ormco, erasers, hardware: the Apple brand tablet with specs Dual-core $1 \mathrm{GHz}$ Cortex-A9

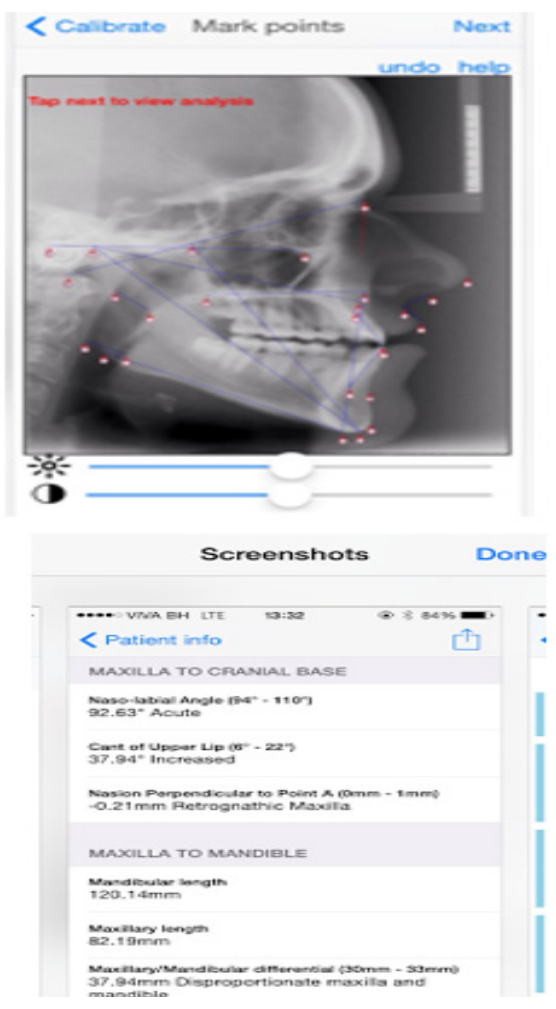

Figure a. Landmark of Steiner's reference points; b. Landmark of Steiner's planes reference 
Table 1. Data normality test

\begin{tabular}{|c|c|c|c|c|c|}
\hline Variable & Group & $\mathrm{n}$ & $\mathrm{p}$-value & Data Distribution & Comparison Test \\
\hline \multirow{2}{*}{ SNA } & Ceph & 32 & 0.344 & Normal & \multirow{2}{*}{ Independent $\mathrm{t}$ tes } \\
\hline & Manual & 32 & 0.274 & Normal & \\
\hline \multirow{2}{*}{ SNB } & Ceph & 32 & 0.000 & Abnormal & \multirow{2}{*}{ Mann whitney test } \\
\hline & Manual & 32 & 0.000 & Abnormal & \\
\hline \multirow{2}{*}{ ANB } & Ceph & 32 & 0.848 & Normal & \multirow{2}{*}{ Independent $\mathrm{t}$ tes } \\
\hline & Manual & 32 & 0.334 & Normal & \\
\hline \multirow{2}{*}{ Mandibular Plane to SN } & Ceph & 32 & 0.943 & Normal & \multirow{2}{*}{ Independent $\mathrm{t}$ test } \\
\hline & Manual & 32 & 0.771 & Normal & \\
\hline \multirow{2}{*}{ Occlusal to SN } & Ceph & 32 & 0.649 & Normal & \multirow{2}{*}{ Independent $\mathrm{t}$ test } \\
\hline & Manual & 32 & 0.321 & Normal & \\
\hline \multirow{2}{*}{ INA Angle } & Ceph & 32 & 0.098 & Normal & \multirow{2}{*}{ Independent $\mathrm{t}$ tes } \\
\hline & Manual & 32 & 0.154 & Normal & \\
\hline \multirow{2}{*}{ INB Angle } & Ceph & 32 & 0.756 & Normal & \multirow{2}{*}{ Independent $\mathrm{t}$ test } \\
\hline & Manual & 32 & 0.369 & Normal & \\
\hline \multirow{2}{*}{ Inter Incisal } & Ceph & 32 & 0.864 & Normal & \multirow{2}{*}{ Mann Whitney test } \\
\hline & Manual & 32 & 0.000 & Abnormal & \\
\hline \multirow{2}{*}{ INA (mm) } & Ceph & 32 & 0.085 & Normal & \multirow{2}{*}{ Independent $\mathrm{t}$ tes } \\
\hline & Manual & 32 & 0.135 & Normal & \\
\hline \multirow{2}{*}{ INB (mm) } & Ceph & 32 & 0.198 & Normal & \multirow{2}{*}{ Independent $t$ tes } \\
\hline & Manual & 32 & 0.171 & Normal & \\
\hline
\end{tabular}

Note: normality test is obtained by the method of shapiro wilk, normal distribution of data if $p>0.05$

Table 2. Cephalometric analysis comparative test for each variable

\begin{tabular}{|c|c|c|c|c|c|}
\hline Variable & Group & $\mathrm{n}$ & Mean (SD) & t count/ MW & $\mathrm{p}$-value \\
\hline \multirow{2}{*}{ SNA } & Ceph & 32 & $81.51(5.95)$ & \multirow{2}{*}{$-0.462^{\text {a) }}$} & \multirow{2}{*}{0.646} \\
\hline & Manual & 32 & $82.2(6.08)$ & & \\
\hline \multirow{2}{*}{ SNB } & Ceph & 32 & 77.09 (13.18) & \multirow{2}{*}{457.000 b) } & \multirow{2}{*}{0.460} \\
\hline & Manual & 32 & $77.8(13.11)$ & & \\
\hline \multirow{2}{*}{ ANB } & Ceph & 32 & $1.93(2.88)$ & \multirow{2}{*}{$-0.243^{\text {a) }}$} & \multirow{2}{*}{0.809} \\
\hline & Manual & 32 & $2.11(3.08)$ & & \\
\hline \multirow{2}{*}{ Mandibular Plane to SN } & Ceph & 32 & $32.79(5.86)$ & \multirow{2}{*}{$0.245^{\text {a) }}$} & \multirow{2}{*}{0.807} \\
\hline & Manual & 32 & $32.42(6.26)$ & & \\
\hline \multirow{2}{*}{ Occlusal to SN } & Ceph & 32 & $18.86(5.8)$ & \multirow{2}{*}{0.279 a) } & \multirow{2}{*}{0.781} \\
\hline & Manual & 32 & $18.47(5.54)$ & & \\
\hline \multirow{2}{*}{ INA Angle } & Ceph & 32 & $25.49(10.48)$ & \multirow{2}{*}{$-0.615^{\text {a) }}$} & \multirow{2}{*}{0.541} \\
\hline & Manual & 32 & $27.09(10.45)$ & & \\
\hline \multirow{2}{*}{ INB Angle } & Ceph & 32 & $26.35(7.97)$ & \multirow{2}{*}{$-0.676^{\text {a) }}$} & \multirow{2}{*}{0.501} \\
\hline & Manual & 32 & 27.67 (7.64) & & \\
\hline \multirow{2}{*}{ Inter Incisal } & Ceph & 32 & $126.46(15.17)$ & \multirow{2}{*}{$459.000^{b)}$} & \multirow{2}{*}{0.477} \\
\hline & Manual & 32 & $117.44(33.36)$ & & \\
\hline \multirow{2}{*}{ INA (mm) } & Ceph & 32 & $7,39(3,25)$ & \multirow{2}{*}{$-0.496^{\text {a) }}$} & \multirow{2}{*}{0.622} \\
\hline & Manual & 32 & $7,81(3,51)$ & & \\
\hline \multirow{2}{*}{ INB (mm) } & Ceph & 32 & $6,41(2,35)$ & \multirow{2}{*}{$-1.111^{\text {a) }}$} & \multirow{2}{*}{0.271} \\
\hline & Manual & 32 & $7,09(2,56)$ & & \\
\hline
\end{tabular}

Note: a) Independent t-test, b) Mann Whitney test, significant differences if the $p$-value $<0.05$, Highly significant if $p<0.01$ 
Table 3. Cephalometric analysis comparative test with multivariate analysis

\begin{tabular}{lcc}
\hline Statistic tests & Statistic & p-value \\
\hline Pillai's Trace & 0,053 & 0,979 \\
Wilks' Lambda & 0,947 & 0,979 \\
Hotelling's Trace & 0,056 & 0,979 \\
Roy's Largest Root & 0,056 & 0,979 \\
\hline
\end{tabular}

Memory 16/32/64 GB, 512 MB RAM, VGA:ATI Mobility Radeon HD547; software: iOS 4, CephNinja application from Naveen Madan. The object of this study was the $\mathrm{x}$-rays of patients treated in the Installation of Department of Orthodontics Integrated Services Dental Hospital Universitas Padjadjaran, men or women to be treated using fixed orthodontic appliance since May 2015 until July 2015 and possessed a negative films and digital cephalogram.

This study procedure involved taking 32 cephalometric samples from patients who were treated with fixed orthodontic appliance in the installation. Cephalometric analysis was then performed using conventional techniques and digital techniques by using application CephNinja software.

Steiner cephalometric analysis using conventional techniques was performed by tracing the $x$-rays on acetate paper. On each sample cephalogram, the determination of Steiner's reference points, lines and planes dragging, angle and distance measurement using protractors were conducted. The same $x$-ray was converted into digital format and the file was inserted into the iOS device using CephNinja application software that had previously calibrated between manual and digital cephalogram on the software. Reference points, lines, and planes were then determined, angle and distance measurements were made, and results that came out in the CephNinja application software were noted.

After Steiner cephalometric analysis measurements were obtained in both conventional and digital methods using CephNinja application software, the results were then inserted into the table and then analyzed statistically.

\section{RESULTS}

This study was conducted on the x-rays of patients treated in the Installation of Department of Orthodontics Integrated Services Dental Hospital Universitas Padjadjaran, men or women to be treated using fixed orthodontic appliance since May 2015 until July 2015 and possessed a negative films and digital cephalogram. It involved 32 cephalometric samples from patients. Cephalometric analysis was then performed using conventional techniques and digital techniques by using application CephNinja software in order to compare any discrepancy between the two methods. Therefore, the data normality test of both analysis groups was conducted, with the following results in Table 1.

Based on Table 1, it was known that 8 out of 10 cephalometric variables showed normal data distribution in both group ( $p>0.05)$, while two other variables, the SNB variables and manual Inter incisal group, showed abnormally distributed data, $(p<0.05)$. Thus, the eight variables with both normally distributed data groups were analyzed using t-test to compare two independent samples, while the comparisons of SNB and Inter incisal were conducted using Mann Whitney test. The results of the comparison tests are presented in Table 2.

Table 2 showed that all 10 cephalometric variables showed no significant difference between the groups analyzed conventionally and the groups analyzed using CephNinja, which is indicated by the $p$-value comparison test results that exceeded the critical point of 0.05 .

In order to obtain the simultaneous comparison of cephalometric analysis (10 variables simultaneously) in both groups, the following multivariate analysis test results were presented

Based on Table 3, it was known that the four methods of multivariate analysis showed $\mathrm{p}$-value of 0.979 , the result exceeded 0.05 , which indicated that overall cephalometric variables in both groups showed no significant difference.

\section{DISCUSSION}

In orthodontic treatment, one analysis conducted for diagnosis and treatment planning is the cephalometric analysis. The most frequently used analysis is the Steiner's analysis because it is quite easy and fast. This analysis is one of the most popular analysis for orthodontic treatment planning and the method itself is a combination of the meth- 
od of Down's, Wendell Wylie, Brodie, Rickett's, Thomson, Riedel, and Holdaway. ${ }^{3}$ Cephalometric analysis can be conducted using two methods: conventional methods, by means of manual tracing; and digital methods using computer.

Research on differences of Steiner cephalometric analysis between conventional method and computerized method using CephNinja application software showed non meaningful results, which means that there is no significant difference between the results of the analysis conducted by tracing conventionally and digital or computerized methods using CephNinja application software. It was shown in Table 2 where there were no significant differences between both groups, which was indicated by the $p$-value comparison test results exceeded the critical point of 0.05 (Table 2) and through four methods of multivariate analysis which showed $p$-value results that exceeded 0.05 , which indicated that overall cephalometric variables in both groups showed no significant difference (Table 3).

This was in line with the statement of Erkan $^{1}$ which stated that the use of computer software to analyze cephalometric allowed clinicians to perform measurements of angles and distances automatically so as to eliminate errors when drawing the line between landmarks or measuring angles by using protractor and of the results showed no difference between the results of the tracing method analysis and the digital method. This show that the used of cephalometric analysis with computer software can replace the use of conventional cephalometric analysis according to research conducted by Cavdar there is a weakness in conventional methods for example the conventional methods take a long time in the process and has a risk of calculation errors in the identifying landmarks, angle and distances. However, further research using other analysis methods with numerous samples was required in order to obtain more significant results to compare the difference between cephalometric analysis using convention- al tracing and digital method, in this case using the CephNinja application software.

\section{CONCLUSION}

This study concluded that there was no significant difference of Steiner cephalometric analysis conducted using conventional tracing and digital method using CephNinja application software.

\section{REFERENCES}

1. Erkan M. Reliability of four different computerized cephalometric analysis programs. Eur J Orthod 2011;34:318-21.

2. Athanasiou AE. Orthodontic cephalometry. London: Mosby-Wolfie; 1995. p. 231-7.

3. Kusnoto. Penggunaan cephalometri radiografi dalam bidang ortodonti. Jakarta; 1977.

4. Guedes PDA, Nascimento de Souza JE. Tuji FM, Nery EM. A comparative study of manual vs. computerized cephalometric analysis. Dent Press J Orthod 2010;15(2):44-51.

5. Ilic Z, Sisul A, Dautovc ML, Laganin S, Dzemidzic V. Manual vs. computerized cephalometric analysis-A comparative study. Conference Proceeding SEJODR 2014, Abstract.

6. Leonardi R, Giordano D, Maiorana F, Spampinato $C$. Automatic cephalometric analysis. Angle Orthod 2008:78(1):145-51.

7. Cavdar K, Ciger S, Zeynepos A. A Comparison of conventional and computerized cephalometric methods. Clin Dent Res 2011;35(1):33-40.

8. Downs WB. The role of cephalometry in orthodontic surgical simulation, prediction and post operative evaluation Precission. Int J Oral Maxillofac Surg 1952;21:199-203

9. Jacobson A, Caufield PW. Introduction to radiographic cephalometry. Philadelphia: Lea \& Febiger; 1985.

10. Whaites E, Drage N. Essentials of dental radiography and radiology. London: Churchill Livingstone; 2013. 